\title{
Evaluasi Sistem Penjaminan Mutu Internal Program Studi S1 Pendidikan Guru Pendidikan Anak Usia Dini
}

\author{
Yoga Aditia Ragil ${ }^{{ }_{1}}$, Sri Martini Meilani² ${ }^{2}$ Zarina Akbar ${ }^{3}$ \\ Pendidikan Anak Usia Dini, Universitas Negeri Jakarta \\ DOI: $\underline{10.31004 / \text { obsesi.v4i2.420 }}$
}

\begin{abstract}
Abstrak
Sistem Penjaminan Mutu Internal (SPMI) belum menjadi prioritas oleh sebagian besar Perguruan Tinggi bila dibandingkan Sistem Penjaminan Mutu Eksternal (SPME). Amanah Undang-Undang Nomor 12 Tahun 2012 tentang Pendidikan Tinggi menyatakan SPMI dan SPME merupakan bagian dari suatu sistem. Diduga SPMI oleh sebagian Perguruan Tinggi tidak memberikan dampak yang signifikan seperti SPME dimana Perguruan Tinggi akan mendapatkan hasil Akreditasi. Penelitian ini dilakukan pada periode Agustus sampai dengan Desember 2019. Tujuan penelitian ini dalam rangka mengevaluasi Program SPMI yang dikembangkan oleh Program Studi Pendidikan Anak Usia Dini (PAUD) yang terakreditasi C. Metode pengkajian dilakukan menggunakan pendekatan sistem meliputi aspek konteks, input, proses, dan output, dengan mengacu kepada studi literatur pada hasilhasil penelitian yang relevan. Hasil pelaksanaan SPMI pada prodi PAUD sudah berjalan dengan baik, bila dibandingkan dengan PPEPP seluruh aspek sudah ditahap pelaksanaan. Rekomendasi evaluasi SPMI pada penelitian ini ditujukan kepada tiga pemangku kepentingan yaitu Direktorat Penjaminan Mutu, Lembaga Penjaminan Mutu tingkat Universitas, dan pimpinan Program Studi.
\end{abstract}

Kata Kunci: spmi; spme; pendidikan anak usia dini; paud; akreditasi.

\begin{abstract}
Internal Quality Assurance System (SPMI) has not been a priority by most universities when compared to the External Quality Assurance System (SPME). The mandate of Law Number 12 of 2012 on Higher Education states that SPMI and SPME are part of a system. It is suspected that SPMI by some Higher Education institutions does not have a significant impact like SPME where Universities will get Accreditation results. This research was conducted in the period August to December 2019. The purpose of this study was in order to evaluate the SPMI Program developed by the Accredited Early Childhood Education Program (PAUD) C. The assessment method was carried out using a systems approach covering aspects of context, input, process, and output, with reference to the study of literature on relevant research results. The results of the implementation of SPMI in PAUD study programs have been going well, when compared to PPEPP all aspects of the implementation stage. The SPMI evaluation recommendations in this study were aimed at three stakeholders, namely the Directorate of Quality Assurance, the University-level Quality Assurance Agency, and the Head of the Study Program.
\end{abstract}

Keywords: spmi; spme; early childhood education; paud; accreditation.

Copyright (c) 2020 Yoga Aditia Ragil, Sri Martini Meilani, Zarina Akbar

$\triangle$ Corresponding author:

Email Address : yogaaditiaragil03@gmail.com (Tangerang Selatan, Indonesia)

Received 7 January 2020, Accepted 11 January 2020, Published 11 January 2020 


\section{PENDAHULUAN}

Pemerintah melalui Undang-Undang No 12 Tahun 2012 Tentang Pendidikan Tinggi pada Pasal 4 butir b menyebutkan bahwa Pendidikan Tinggi berfungsi mengembangkan Sivitas Akademika yang inovatif, responsif, kreatif, terampil, berbudaya saing, dan kooperatif melalui pelaksanaan Tridharma Perguruan Tinggi (Indonesia, 2012). Perguruan Tinggi dapat mengembangkan sendiri budaya akademik bagi Sivitas Akademika yang berfungsi sebagai komunitas ilmiah yang berwibawa dan mampu melakukan interaksi yang mengangkat martabat bangsa Indonesia dalam pergaulan internasional. Kualitas pelayanan harus dapat mendukung kenyamanan dan kesenangan peserta didik sehingga peserta didik dapat melaksanakan tugas dan kewajibannya (Dirwan, 2014). Nilai yang dimiliki dari setiap Perguruan Tinggi adalah dapat diukur dari lembaga akreditasi yang legal.

Akreditasi merupakan kegiatan penilaian sesuai dengan kriteria yang telah ditetapkan berdasarkan Standar Nasional Pendidikan Tinggi. Positive effects of accreditation in line with the effects found in many different industries and sectors of the usage of quality management (Lagrosen, 2017). Pernyataan tersebut dapat diartikan bahwa efek positif dari akreditasi sejalan dengan efek yang ditemukan di berbagai industri dan sektor penggunaan kualitas pengelolaan. Manfaat yang dapat diambil dari Perguruan Tinggi dan Program Studi dengan adanya akreditasi adalah adanya penilaian yang dilakukan oleh Badan Akreditasi Nasional, sehingga baik Perguruan Tinggi dan Program Studi tersebut dapat bersaing di dalam pasar pendidikan.

There is a clear case that the government has an important role to play in higher education financing. (Long, 2019). Hal tersebut dapat diartikan bahwa pemerintah memiliki peran penting dalam pendidikan tinggi dalam hal pembiayaan. Sehingga dapat dipastikan bahwa untuk meningkatkan kualitas perguruan tinggi untuk meningkatkan nilai pasar dalam dunia pendidikan harus dari instansi masing-masing dengan cara meningkatkan kualitas dari masing-masing perguruan tinggi. Pelaksanaan akreditasi yang ada dapat diawali dengan pelaksanaan Sistem Penjaminan Mutu Internal atau yang biasa disebut dengan SPMI dilakukan oleh internal Perguruan Tinggi dan Program Studi.

Penjaminan mutu menjadi tujuan utama dari Undang-Undang No 12 Tahun 2012 Tentang Pendidikan Tinggi pada Bab III yang menyebutkan bahwa Pendidikan Tinggi yang bermutu merupakan Pendidikan Tinggi yang menghasilkan lulusan yang mampu secara aktif mengembangkan potensinya dan menghasilkan Ilmu Pengetahuan dan/atau Teknologi yang berguna bagi masyarakat, bangsa, dan negara. Indicate that time is required for the quality assurance Time is needed for each individual to take responsibility for quality and to develop a culture of quality enhancement and quality assurance in each unit as a professional way of life (Ezer \& Horin, 2013). Pernyataan tersebut dapat diartikan bahwa diperlukan waktu untuk jaminan kualitas. Waktu diperlukan untuk setiap individu bertanggung jawab atas kualitas dan mengembangkan budaya peningkatan kualitas dan jaminan kualitas di setiap unit sebagai proses kerja profesional. Penerapan Sistem Penjaminan Mutu Internal di Perguruan Tinggi sangat penting dalam meningkatkan mutu, sehingga diharapkan dapat menghasilkan lulusan yang sesuai dengan apa yang diharapkan.

Faktor yang paling memacu gerakan penjaminan mutu adalah keharusan perguruan tinggi untuk menyelenggarakan penjaminan mutu internal, di mana penjaminan mutu di perguruan tinggi secara keseluruhan sangat penting karena sasaran pendidikan bukan hanya untuk akademik semata, akan tetapi lulusan yang mempunyai budaya mutu. Sistem Penjaminan Mutu Internal dibuat sebagai dasar untuk mengendalikan pengelolaan pendidikan tinggi bermutu dengan standar nasional dan memenuhi peraturan pemerintah Republik Indonesia (Fitrah, Ruslan, \& Hendra, 2018). Hasil dari Sistem Penjaminan Mutu Internal inilah yang nanti akan dijadikan dasar untuk menyusun Sistem Penjaminan Mutu Eksternal oleh Program Studi dan Perguruan Tinggi atau reakreditasi yang nantinya dapat membuat dasar penilaian untuk Perguruan Tinggi. 
Seiring berjalannya waktu, sudah banyak Perguruan Tinggi yang berdiri mulai dari nilai akreditasi $\mathrm{C}$ sampai dengan A sehingga tidak bisa dipungkiri bahwa selalu ada persaingan antara masing-masing Perguruan Tinggi dalam pasar pendidikan. Colleges have had to compete in a quasi-education market and this has necessitated many changes, not least the movement to some mechanism of self assessment (Stoten, 2012). Hal tersebut dapat diartikan bahwa mekanisme pelayanan yang ada di masing-masing Perguruan Tinggi tidak hanya berbasis kuantitas tetapi diperlukan juga aspek kualitas.

Dalam bidang pendidikan tinggi peningkatan mutu di segala bidang merupakan tuntutan yang harus dilaksanakan dengan segera. Manajemen perguruan tinggi belum tertata dengan baik karena masih lemahnya komitmen birokrat dan pengelolaan pendidikan tinggi untuk mencapai keunggulan. Selain itu kurangnya kecakapan pengelola pendidikan tinggi dengan spektrum tugas maupun masalah pendidikan yang semakin kompleks, dan masih terdapat pengelola pendidikan tinggi yang tidak memiliki latar belakang disiplin ilmu pendidikan (Yuliawati, 2012). Pelaksanaan kebijakan pimpinan yang terdapat di Perguruan Tinggi secara berkesinambungan akan dikaitkan dengan turunan dari Perguruan Tinggi ke Fakultas dan Program Studi.

Kualitas budaya mutu Program Studi merupakan tanggung jawab dari segera unsur yang ada di dalamnya. Komitmen pimpinan Program Studi hanya tertuju kepada Sistem Penjaminan Mutu Eksternal atau lembaga akreditasi yang dapat memberikan nilai terhadap dokumen atau pelaksanaan dari masing-masing Program Studi. Development and consolidation of such a quality culture, are adequate strategic planning, proper organizational structures, adequate internal evaluation processes, committed institutional leadership, active participation of academic and administrative staff, and integrated information system for data collection and analysis (Santos \& Dias, 2017). Data tersebut dapat diartikan bahwa diperlukan komitmen dari pimpinan Perguruan Tinggi dalam pelaksanaan menjamin kualitas Program Studi.

Salah satu Program Studi unggulan saat ini adalah Pendidikan Anak Usia Dini. Dijelaskan di dalam Peraturan Menteri Pendidikan dan Kebudayaan Republik Indonesia Nomor 137 Tahun 2014 tentang Standar Nasional Pendidikan Anak Usia Dini pada Bab I pasal 1 butir 10 bahwa Pendidikan Anak Usia Dini adalah upaya pembinaan yang ditujukan kepada anak sejak lahir sampai usia 6 (enam) tahun yang dilakukan melalui pemberian rancangan pendidikan untuk membantu pertumbuhan dan perkembangan jasmani dan rohani agar anak memiliki kesiapan dalam memasuki pendidikan lebih lanjut. Tujuan dari program Studi Pendidikan Anak Usia Dini adalah dapat memberikan fasilitas yang memadai dalam proses pembelajaran termaksud kualitas mutu dari Program Studi Pendidikan Anak Usia Dini melalui pelaksanaan Sistem Penjaminan Mutu Internal.

Penjaminan mutu Pendidikan Tinggi merupakan kegiatan sistemik untuk meningkatkan mutu Pendidikan Tinggi secara berencana dan berkelanjutan, dengan dilakukan melalui penetapan, pelaksanaan evaluasi, pengendalian, dan peningkatan standar Pendidikan Tinggi. Institutions should have a policy for quality assurance that is made public and forms part of their strategic management (Manatos, Sarrico, \& Rosa, 2017). Lembaga harus memiliki kebijakan untuk penjaminan kualitas yang dipublikasikan dan menjadi bagian dari manajemen strategisnya. Namun tidak setiap Program Studi memilik data penunjang kualitas secara lengkap, sehingga terlihat masih kurangnya koordinasi terkait dengan pengadaan dokumen yang dibutuhkan untuk proses pelaksanaan Sistem Penjaminan Mutu Internal untuk Program Studi.

Keberhasilan dalam penerapan Sistem Penjaminan Mutu Internal adalah pemahaman dari komitmen pimpinan dalam menyusun strategi manajemen informasi yang tepat. Ideally, internal QA units or committees should have access to top-level managers as well as having the social skills to communicate effectively with faculty members and students; this is critical to the effective strategic deployment of internal QA and to successful information management (M. Mourad, 2016). Peningkatan kualitas masing-masing Perguruan Tinggi khususnya untuk Program Studi diperlukan komitmen dari pimpinan dalam melaksanakan Sistem Penjaminan Mutu Internal untuk mengevaluasi diri Program Studi. 
Program studi perlu membentuk Tim Evaluasi Hasil Belajar, Evaluasi Program, dan Evaluasi Diri. Pelaksanaan evaluasi program sebaiknya tidak hanya pada akhir pelaksanaan program. Pemantauan terhadap proses pelaksanaan program perlu dilakukan untuk memberikan masukan perbaikan sehingga program dapat berlangsung dengan baik (Supriyadi, 2017). Namun dewasa ini, proses penjaminan mutu atau audit internal hanya dilakukan pada saat menghadapi proses pengajuan akreditasi maupun reakreditasi. Padahal pelaksanaan penjaminan mutu atau audit internal perlu secara rutin dilakukan, yang bertujuan untuk mengevaluasi diri untuk mendapatkan kualitas yang lebih baik.

Evaluasi diri merupakan cara untuk mengetahui dengan tepat kemampuan dan kondisi tantangan yang harus dihadapi baik bagi perorangan maupun untuk lembaga instansi manapun. Finally elaborated national systems of school self-evaluation, what needs more support is the capacity of schools and teachers to genuinely sansee the developmental possibilities (Capperucci, 2015). Sistem evaluasi diri sekolah terlihat rumit, lebih banyak memerlukan dukungan dari komponen sekolah dan guru untuk benar-benar melihat kemungkinan perkembangan.

Bila pelaksanaan Sistem Penjaminan Mutu Internal dari masing-masing Perguruan Tinggi sudah berjalan dengan baik, maka bisa dipastikan bahwa Sistem Penjaminan Mutu Eksternal dari Perguruan Tinggi tersebut juga sudah berjalan dengan baik. Tetapi bila hasil dari Sistem Penjaminan Mutu Eksternal dari masing-masing Perguruan Tinggi sudah mendapatkan hasil yang baik, hal tersebut belum bisa dipastikan bahwa pelaksanaan Sistem Penjaminan Mutu Internalnya sudah berjalan dengan baik. Menurut data yang didapat dari Badan Akreditasi Nasional Pendidikan Tinggi menyatakan bahwa terdapat 252 Program Studi Pendidikan Anak Usia Dini. Lebih lanjut data tersebut diperjelas bahwa sebanyak 12 Prodi dengan status A atau sekitar 4,56\%, sebanyak 111 Prodi dengan status B atau sekitar 42,21\%, dan sebanyak 140 Prodi dengan status C atau sekitar 53,23\%. Hal tersebut dapat dilihat lebih rinci di Tabel 1:

Tabel 1. Daftar Akreditasi Prodi Pendidikan Anak Usia Dini

\begin{tabular}{cccccccc}
\hline No & Akreditasi & S1 & S2 & Jumlah & S1 (\%) & S2 (\%) & Seluruh (\%) \\
\hline $\mathbf{1}$ & A & 9 & 3 & 12 & 3,57 & 27,27 & 4,56 \\
\hline $\mathbf{2}$ & B & 104 & 7 & 111 & 41,27 & 63,64 & 42,21 \\
\hline $\mathbf{3}$ & C & 139 & 1 & 140 & 55,16 & 9,09 & 53,23 \\
\hline & Jumlah & $\mathbf{2 5 2}$ & $\mathbf{1 1}$ & $\mathbf{2 6 3}$ & $\mathbf{1 0 0}$ & $\mathbf{1 0 0}$ & $\mathbf{1 0 0}$ \\
\hline
\end{tabular}

(sumber: BAN-PT)

Hal tersebut harus menjadi perhatian mengingat Program Studi Pendidikan Anak Usia Dini merupakan Program Studi yang difokuskan menangani proses tumbuh kembang anak dalam usia emas, sehingga diperlukan perbaikan kualitas dalam pelayanan bidang akademik maupun dalam meningkatkan budaya mutu untuk Program Studi Pendidikan Anak Usia Dini.

Budaya mutu sudah semestinya menjadi bagian dari budaya kerja akademik di Indonesia. Hal tersebut dipertegas dengan terbitnya Peraturan Menteri Riset, Teknologi, dan Pendidikan Tinggi Nomor 44 Tahun 2015 yang konsen dalam hal mengembangan mutu pendidikan yang bersifat internal yang lazim dengan istilah SPMI dan yang bersifat eksternal yang dilakukan oleh BAN-PT. Namun dewasa ini sangat sulit untuk menjamin mutu dari penyelenggara pendidikan tersebut yang salah satu alasannya tentang pendanaan. Untuk menwujudkan pendidikan yang bermutu memang butuh biaya, tetapi ketidaksesuaian biaya dengan standar yang telah ditetapkan tidak serta merta membuat pendidikan bermutu akan terwujud (Maksum, 2016). Pendidikan yang tidak bermutu tidak hanya merugikan bagi lulusan tersebut, tetapi juga merugikan instansi dan dalam jangka 
panjang akan merugikan bangsa. Tujuan dan manfaat dari penelitian ini adalah guna memastikan kualitas penyelenggaraan pendidikan yang dilaksanakan oleh Program Studi dan memastikan kualiatas lulusan dari Program Studi Pendidikan Anak Usia Dini yang diukur dari Sistem Penjaminan Mutu Internal, sehingga setiap Perguruan Tinggi dapat bersaing di dalam pasar pendidikan.

\section{METODOLOGI}

Pendekatan yang digunakan dalam penelitian ini adalah pendekatan penelitian evaluasi program. Penelitian evaluasi program adalah upaya untuk mengukur hasil atau dampak suatu aktivitas, program atau proyek dengan cara membandingkan dengan tujuan yang telah ditetapkan, dan bagaimana cara mencapainya. Berkaitan dengan fokus penelitian, pendekatan yang akan digunakan dalam penelitian ini adalah penelitian evaluasi (evaluation research) program dengan menggunakan pendekatan kualitatif yang bersifat deskriptif. Pendekatan kualitatif merupakan salah satu pendekatan yang secara primer menggunakan paradigma pengetahuan berdasarkan pandangan konstruktif atau pandangan advokasi atau keduanya.

Untuk belajar dari pengalaman lingkungan, perlu dipahami berbagai pengalaman yang terjadi dan tindakan seperti apa yang dilakukan oleh orang yang terlibat di dalam masalah tersebut. Conducting qualitative research involves many and different choices for the researcher (Crescentini, Mainardi, \& Pedagogica, 2014). Melakukan penelitian kualitatif memberikan banyak pilihan bagi para peneliti. Peneliti dipandang perlu meningkatkan kreativitas dalam proses penelitian karena peneliti merupakan intrumen dalam penelitian tersebut.

Metode Kualitatif dirancang untuk membantu para peneliti memahami orang dan apa yang mereka katakan dan lakukan. Mereka dirancang untuk membantu para peneliti memahami konteks sosial dan budaya dimana orang tinggal (Myers, 2014). Penelitian kualitatif berpendapat bahwa hampir tidak mungkin untuk memahami mengapa seseorang melakukan sesuatu terjadi dalam suatu organisasi tanpa berbicara dengan orang tentang hal itu.

Pendekatan dalam penelitian ini menggunakan model evaluasi formatif dan sumatif yang dikembangkan oleh Stufflebem yaitu model evaluasi CIPP. Evaluasi formatif mencakup evaluasi komponen-komponen konteks, input, proses, dan product. Sedangkan evaluasi summative mencakup komponen produk. Model evaluasi ini memberikan kajian yang komprehensif terhadap komponen-komponen yang mendasar, yaitu: (1) Penentuan informasi yang diperlukan berdasarkan perumusan masalah; (2) Penentuan teknik pengumpulan informasi yang diperlukan; (3) Penentuan teknik pengumpulan informasi sesuai dengan jenis dan sumber informasi; (4) Penentuan instrumen untuk mengumpulkan informasi; dan (5) Analisis data sesuai dengan informasi yang dikumpulkan

Penelitian evaluasi program Sistem Penjaminan Mutu Internal adalah dengan menggunakan model CIPP karena hasil evaluasinya diperuntukan pada pengambilan keputusan berdasarkan pelaksanaan dan keterlaksanaan program. Selanjutnya menghasilkan rekomendasi untuk keberlanjutan program pelaksanaan pendidikan karakter di masa yang akan datang. Sedangkan rekomendasi yang dinantikan biasanya juga berisi tiga kemungkinan yaitu : (1) program berhasil dan perlu diteruskan; (2) program diteruskan dengan modifikasi sebagian atau sebagian besar; (3) program berikutnya diberhentikan karena tujuan tidak tercapai.

Adapun teknik pengumpulan data yang dilakukan dalam penelitian metode kualitatif adalah dengan cara pengamatan (observasi), wawancara, dan dokumentasi. Untuk memperoleh data-data yang dibutuhkan dalam penelitian, maka digunakan teknik pengumpulan data berupa; observasi, wawancara, dan dokumentasi. 
Analisis data dalam penelitian kualitatif dilakukan pada saat pengumpulan data berlangsung, dan setelah pengumpulan data dalam periode tertentu. In analyzing qualitative data, researchers often make use of cyclical data analysis (Mackey, 2010). Dalam menganalisis data kualitatif, peneliti sering menggunakan siklus analisis data. Analisis data yang dilakukan dalam penelitian kualitatif yaitu melalui proses reduksi data, penyajian data, dan kesimpulan (verifikasi).

Reduksi data merupakan proses pemilihan, pemusatan perhatian pada penyederhanaan data, dan merinci data kasar dari hasil catatan lapangan, catatan wawancara, dan catatan dokumentasi. Data-data yang telah didapatkan akan dipilih yang penting dan membuang yang tidak diperlukan dan dipilih tema serta polanya berdasarkan data-data tersebut. Setelah data yang didapat dan dianalisis secara mendalam maka langkah selajutnya adalah menarik kesimpulan dari data yang telah dianalisis. Kesimpulan awal yang dikemukakan masih bersifat sementara dan kemungkinan akan berubah saat penelitian di lapangan, tetapi jika kesimpulan yang didapat pada tahap awal konsisiten saat peneliti kembali lagi ke lapangan maka kesimpulan yang dikemukakan bersifat kredibel.

\section{HASIL DAN PEMBAHASAN}

Penelitian yang dilakukan oleh Putri Ratih Puspitasari yang berjudul Evaluasi Program Pelatihan Pendidikan Holistik Berbasis Karaktek menjelaskan bahwa pelatihan perlu diselaraskan dengan kerangka kerja nasional Indonesia (KKNI) dan tersertifikasi sehingga mengacu pada suatu standar yang telah ditetapkan dan diakui keberadaannya baik secara nasional, regional maupun internasional. Menegemen pelatihan sebaiknya dilaksanakan di bawah koordinasi lembaga penjaminan mutu pendidikan (LPMP) atau lembaga independen yang diakui, serta berkoordinasi dengan lembaga Pendidikan dan Tenaga Kependidikan (LPTK) sehingga konversi nilai pelatihan dapat diakui.

Evaluasi dalam penelitian ini menfokuskan pada Sistem Penjaminan Mutu Internal yang terdapat dari Perguruan Tinggi Peneliti berdasarkan Undang-Undang Republik Indonesia Nomor 12 Tahun 2012 tentang Pendidikan Tinggi, Peraturan Menteri Riset, Teknologi, dan Pendidikan Tinggi Nomor 44 Tahun 2015 tentang Standar Nasional Pendidikan Tinggi, dan Peraturan Menteri Riset, Teknologi, dan Pendidikan Tinggi Nomor 62 Tahun 2016 tentang Sistem Penjaminan Mutu Pendidikan Tinggi. Hasil evaluasi dalam penelitian ini akan disajikan ke dalam beberapa Point sesuai dengan model evaluasi yang dipakai yaitu CIPP yang mencakup aspek Context, Input, Process, Product.

\section{Aspek Kontek (Context)}

Bila disandingkan dengan siklus PPEPP pada aspek Konteks maka dapat dikatakan bahwa Program Studi Pendidikan Anak Usia Dini berada ditahap peningkatan. Hal tersebut ditandai dari segi tata pamong yaitu terdapat organisasi penjaminan mutu di tingkat Program Studi yang disebut dengan Gugus Penjaminan Mutu, untuk membantu peran Program Studi dalam peningkatan mutu Program Studi. Lebih dari itu Program Studi sudah mempunyai beberapa dokumen yaitu (1) Laporan Evaluasi Diri tahun 2018, (2) Akreditasi Program Studi Sarjana tahun 2018, (3) Laporan hasil evaluasi dosen oleh mahasiswa terhadap proses pembelajaran tahun 2016/2017, (4) Kurikulum berbasis KKNI tahun 2017, dan (5) Rencana Strategis Program Studi tahun 2014-2019.

\section{Aspek Masukan (Input)}

Pada aspek masukan dapat dijelaskan bahwa Program Studi Pendidikan Anak Usia Dini di universitas peneliti telah melakukan penyusunan laporan untuk evaluasi diri Program Studi Pendidikan Anak Usia Dini yang tersusun di lemari khusus yang digunakan untuk menyimpan dokumen terkait Sistem Penjaminan Mutu Internal yang juga digunakan sebagai borang akreditasi. Bila disandingkan dengan siklus PPEPP maka dapat dikatakan bahwa Program Studi Pendidikan Anak Usia Dini berada ditahap evaluasi belum pada tahap 
pengendalian, maupun peningkatan dari proses pelaksanaan masukan dokumen yang dimiliki. Hal tersebut dapat dikatakan karena masih ada beberapa dokumen yang tidak pada tempatnya dan masih adanya beberapa standar yang tidak memiliki dokumen pendukungnya.

\section{Aspek Proses (Process)}

Lingkup Sistem Penjaminan Mutu Internal meliputi semua persyaratan sistem yang berpengaruh terhadap mutu layanan. Persyaratan sistem meliputi: dokumen sistem penjaminan mutu, organisasi, komitmen manajemen, sumber daya, dan program kegiatan. Pada aspek proses dapat dijelaskan bahwa Program Studi Pendidikan Anak Usia Dini di universitas peneliti mempunyai dukungan dari pemangku kepentingan baik dalam ranah Universitas, Fakultas, maupun dari Ketua Program Studi Pendidikan Anak Usia Dini. Sehingga program studi Pendidikan Anak Usia Dini sudah melakukan dan menyusun Laporan Evaluasi Diri yang dilakukan pada tahun 2018. Sedangkan untuk faktor penghambat dari pelaksanaan Sistem Penjaminan Mutu Internal yaitu pada unsur Sumber Daya Manusia (SDM) yang terbatas di Program Studi.

Hasil studi dokumentasi terhadap Laporan Evaluasi Diri yang dilakukan oleh Program Studi dapat dikatakan bahwa belum sepenuhnya melaporakan hasil yang ada di Program Studi, tetapi masih banyak pembahasan yang mengarah ke Penjaminan Mutu tingkat Universitas. Selanjutnya Laporan Evaluasi Diri juga masih menggunakan kriteria tahun 2017 yang dikeluarkan oleh BAN-PT dan belum adanya Laporan Evaluasi Diri tahun 2019 dengan menggunakan kriteria baru yang dikeluarkan oleh BAN-PT. Maka dapat disimpulkan bahwa untuk aspek proses untuk Program Studi Pendidikan Anak Usia Dini di Universitas Peneliti berada ditahap Evaluasi.

\section{Aspek Hasil (Product)}

Pada aspek hasil dapat dijelaskan bahwa Program Studi Pendidikan Anak Usia Dini di universitas peneliti sudah merumuskan berbagai strategi yang direkomendasikan untuk menangani kelemahan dan ancaman, termaksud pemecahan masalah, perbaikan dan pengembangan lebih lanjut. Program Studi melaksanakan Rapat Tinjauan Manajemen (RTM) Program Studi yang dihadiri oleh seluruh dosen dan tenaga kependidikan di Program Studi PAUD. RTM dilakukan dengan tujuan untuk membahas tindak lanjut temuan audit dan meninjau kembali Sistem Penjaminan Mutu Internal Program Studi. Dalam rapat ini dibahas temuan yang diperoleh dan dilakukan skala perioritas berdasaran berat ringannya temuan. Temuan yang bersifat observasi dapat disegara ditangani. Hasil yang tidak dapat diselesaikan di tingkat program Studi dapat dibawa ke dalam rapat tinjauan tingkat Fakultas yang dipimpin oleh Dekan dan dihadiri oleh pimpinan Program Studi maupun unit di lingkungan fakultas ilmu keguruan dan pendidikan. Program Studi Pendidikan Anak Usia Dini sudah menentukan prioritas penanganan kelemahan dan acaman tersebut dalam bentuk suatu rencana tindakan untuk melaksanakan program penanganan. Maka dapat disimpulan bahwa untuk aspek hasil untuk Program Studi Pendidikan Anak Usia Dini di Universitas Peneliti berada ditahap Pengendalian.

\section{SIMPULAN}

Sejumlah dokumen yang dapat dijadikan rujukan dalam penyelenggaraan pembelajaran di program studi sudah dimiliki, namun standar yang digunakan masih dengan menggunakan instumen yang lama. Sehingga diperlukan penyusunan dokumen dalam rangka evaluasi diri mengacu kepada sembilan standar untuk pelaksanan Sistem Penjaminan Mutu Internal (SPMI). Program studi sudah mendapatkan dukungan dari tingkat Universitas dan tingkat Fakultas; serta sudah melakukan analisis untuk melihat kekuatan (strengths), kelemahan (weakness), peluang (opportunities), dan ancaman (threats) dengan menggunakan Analisis Swot. 


\section{UCAPAN TERIMAKASIH}

Terima Kasih kepada seluruh pihak yang telah membantu dalam penyelesaian penelitian ini. Kepada Direktorat Penjaminan Mutu Kemenristekdikti, dan kepada Universitas Peneliti.

\section{DAFTAR PUSTAKA}

Capperucci, D. (2015). In che modo l' autovalutazione può rendere le scuole più efficaci How SelfEvaluation can make schools more effective. 15, 258-278.

Crescentini, A., Mainardi, G., \& Pedagogica, A. S. (2014). Qualitative research articles : guidelines , suggestions and needs. 21(July 2009). https:// doi.org/10.1108/13665620910966820

Dirwan, A. (2014). Pengaruh Kualitas Pelayanan dan Komitmen Mahasiswa terhadap Motivasi Berprestasi Mahasiswa Perguruan Tinggi Swasta. Jurnal Cakrawala Pendidikan, 3(3), 379-391. https://doi.org/10.21831/cp.v3i3.2382

Ezer, H., \& Horin, A. (2013). Quality enhancement : a case of internal evaluation at a teacher education college. 21(3), 247-259. https:/ / doi.org/10.1108/QAE-Jul-2011-0041

Fitrah, M., Ruslan, ., \& Hendra, . (2018). Urgensi Sistem Penjaminan Mutu Internal Terhadap Peningkatan Mutu Perguruan Tinggi. Jurnal Penjaminan Mutu, 4(1), 76. https:/ / doi.org/10.25078/jpm.v4i1.400

Indonesia, R. Undang-Undang Republik Indonesia nomor 12 Tahun 2012 Tentang Pendidikan Tinggi., (2012).

Lagrosen, S. O. (2017). Quality through accreditation. International Journal of Quality and Service Sciences, 9(3/4), 469-483. https:/ / doi.org/10.1108/IJQSS-02-2017-0010

Long, N. Van. (2019). Financing higher education in an imperfect world. Economics of Education Review, 71, 23-31. https://doi.org/10.1016/j.econedurev.2018.06.004

M. Mourad. (2016). Quality Assurance as a driver of information management strategy : Stakeholders ' perspectives in Higher Education.

Mackey, A. (2010). Second Language Research - Methodology and Design. New Jersey: Lawrence Erlbaum Associates, Inc., Publishers.

Maksum, A. (2016). Kurikulum dan Pembelajaran di Perguruan Tinggi : (April 2015).

Manatos, M. J., Sarrico, C. S., \& Rosa, M. J. (2017). The European standards and guidelines for internal quality assurance. The TQM Journal, 29(2), 342-356. https:/ / doi.org/10.1108/TQM-01-2016-0009

Myers, M. D. (2014). Penelitian Kualitatif di Manajeman \& Bisnis. Sidoarjo: Zifatama Publisher.

Santos, I. M., \& Dias, G. (2017). A comprehensive internal quality assurance system at University of Minho. International Journal of Quality $\mathcal{E}$ Reliability Management, 34(2), 278-294. https:// doi.org/10.1108/IJQRM-04-2015-0063

Stoten, D. W. (2012). Exploring quality assurance in sixth form colleges. Quality Assurance in Education, 20(3), 259-273. https:/ / doi.org/10.1108/09684881211240312

Supriyadi, E. (2017). Pengembangan model evaluasi untuk meningkatkan mutu pendidikan teknik elektro. Jurnal Edukasi Elektro, 1(1), 25-35. https:// doi.org/10.21831/jee.v1i1.13254

Yuliawati, S. (2012). Pendidikan kajian implementasi tri dharma perguruan tinggi sebagai fenomena pendidikan tinggi di indonesia. Widya, 318(29). 